\title{
Comparison of Awareness of Stroke Warning Signs between Community-Dwelling Stroke Survivors and Families and the General Population without Stroke
}

\author{
Young-Hoon Lee a,b $^{\mathrm{a}, \mathrm{b}}$ \\ aDepartment of Preventive Medicine and Institute of Wonkwang Medical Science, Wonkwang University School of Medicine, Iksan, Korea \\ ${ }^{b}$ Regional Cardiocerebrovascular Center, Wonkwang University Hospital, Iksan, Korea
}

\section{Dear Sir:}

Individuals with a prior history of stroke have an increased risk of recurrent strokes compared to the general population. ${ }^{1,2}$ Moreover, recurrent stroke can lead to worsened functional outcomes and increased mortality. ${ }^{3,4}$ Although stroke patients and their families are expected to have better knowledge of stroke warning signs (SWSs) than the general population, little is known about whether stroke survivors (SS) and/or their family members are more aware of SWS than the general population. A total of 9,245 individuals aged $\geq 40$ years who participated in the 2016 Korea Community Health Survey in the Jeonbuk metropolitan area were included in this study. According to stroke history, respondents were classified as SS, family members of SS (FMSs; any family members who live with SS), and non-stroke controls (NSCs; individuals who were not SS and did not live with SS). Respondents were asked the following close-ended questions to assess their awareness of SWS: "If you think the following symptom is a symptom of stroke, answer 'Yes' or if you do not think so, answer 'No'. If you are not sure, answer 'I do not know." SWS included sudden numbness or weakness $\left(S_{1}\right)$, sudden difficulty in speaking or understanding speech $\left(\mathrm{S}_{2}\right)$, sudden dizziness $\left(S_{3}\right)$, sudden visual impairment $\left(S_{4}\right)$, and sudden severe headache $\left(\mathrm{S}_{5}\right)$. Only those who answered "Yes" to each question were determined to be aware of the corresponding stroke symptom. Compared to NSC, the odds ratios (ORs) and 95\% confidence intervals (Cls) for SWS were calculated for SS and FMS.

Of the total respondents, 382 (4.1\%) were SS, 279 (3.0\%) were FMS, and 8,584 (92.9\%) were NSC. The proportion of individuals knowing $S_{1}$ was significantly higher among the SS group

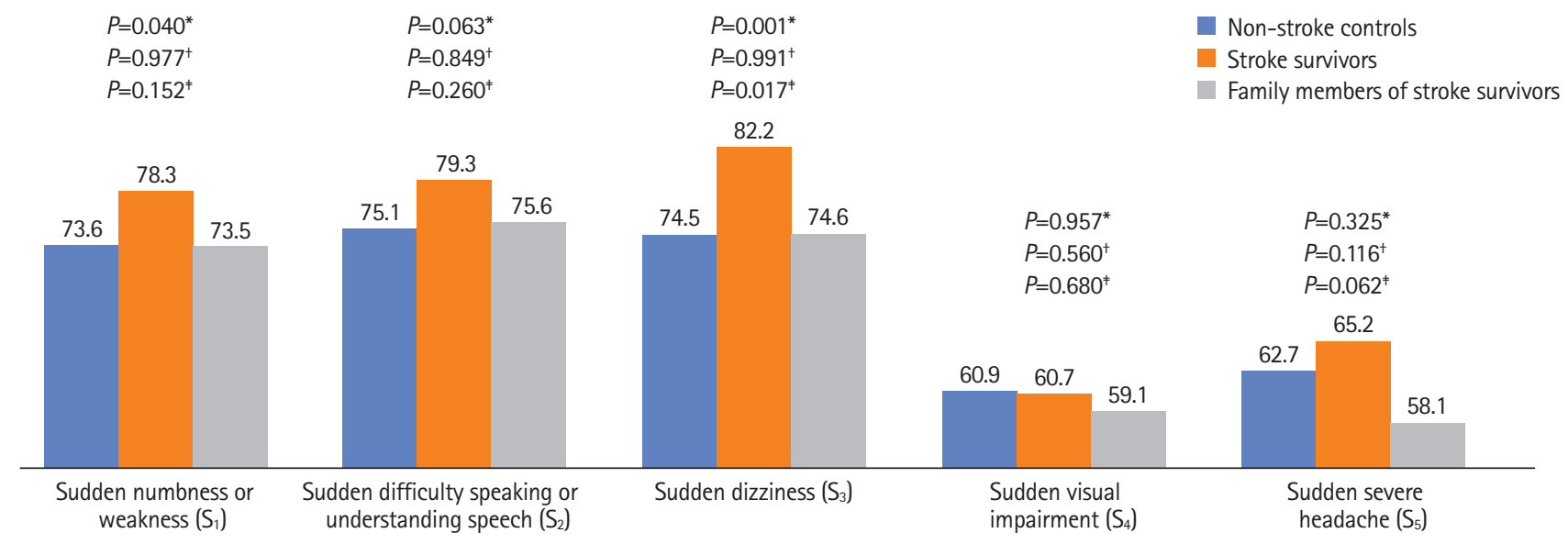

Figure 1. Awareness of individual stroke warning signs by the presence of stroke. ${ }^{*}$ Comparison between non-stroke controls and stroke survivors; ${ }^{+}$Comparison between non-stroke controls and family members of stroke survivors; ${ }^{\ddagger}$ Comparison between stroke survivors and family members of stroke survivors.

This is an Open Access article distributed under the terms of the Creative Commons Attribution Non-Commercial License (http://creativecommons.org/licenses/by-nc/4.0/) which permits unrestricted non-commercial use, distribution, and reproduction in any medium, provided the original work is properly cited. 
(78.3\%) than in the NSC group (73.6\%) $(P=0.040)$. The proportion of people knowing $S_{3}$ was significantly higher in the SS

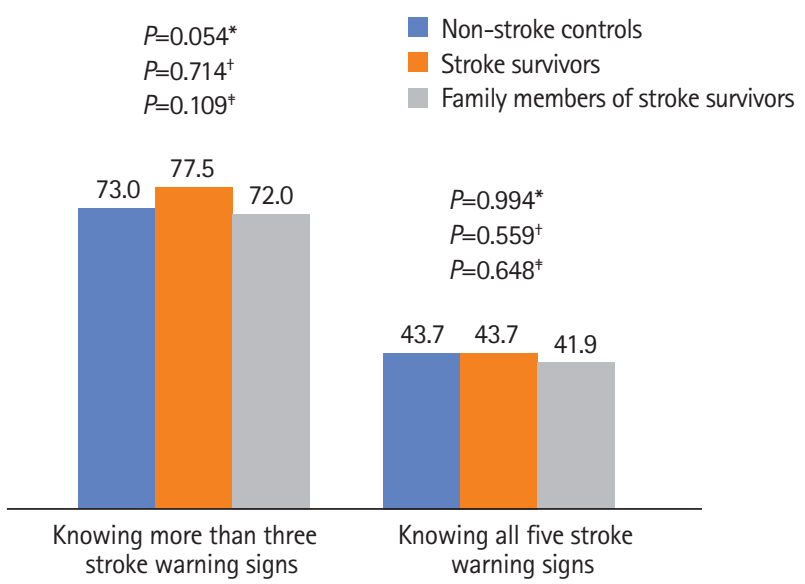

Figure 2. Awareness of knowing more than three or all five stroke warning signs by the presence of stroke. ${ }^{*}$ Comparison between non-stroke controls and stroke survivors; ${ }^{+}$Comparison between non-stroke controls and family members of stroke survivors; ${ }^{\ddagger}$ Comparison between stroke survivors and family members of stroke survivors. group (82.2\%) than in the NSC (74.5\%) and FMS (74.6\%) groups ( $P=0.001$ and $P=0.017$, respectively). However, the proportion of individuals who knew SWS was not significantly different between the FMS and NSC groups (Figure 1). In addition, the proportion of individuals who recognized more than three SWS or all five SWS was not significantly different among the SS, FMS, and NSC groups (Figure 2).

After full adjustments for covariates (model 3), SS had higher ORs for knowing $\mathrm{S}_{1}(\mathrm{OR}, 1.42 ; 95 \% \mathrm{Cl}, 1.10$ to 1.83$), \mathrm{S}_{2}(\mathrm{OR}$, $1.54 ; 95 \% \mathrm{Cl}, 1.19$ to 1.99$), \mathrm{S}_{3}\left(\mathrm{OR}, 1.89 ; 95 \% \mathrm{Cl}_{1} 1.44\right.$ to 2.48$)$, and $\mathrm{S}_{5}(\mathrm{OR}, 1.33 ; 95 \% \mathrm{Cl}, 1.07$ to 1.66$)$ than NSC. Furthermore, SS had a higher OR for knowing more than three SWS (OR, $1.53 ; 95 \% \mathrm{Cl}, 1.19$ to 1.97 in model 3) than NSC. However, compared to NSC, SS did not have a high OR for knowing all SWS $(O R, 1.21 ; 95 \% \mathrm{Cl}, 0.97$ to 1.49 in model 3; $P=0.086$ [borderline significance]). Meanwhile, in all models, there were no significant differences in the ORs for stroke awareness between NSC and FMS (Table 1).

Improved awareness of SWS in high-risk groups, such as those with prior stroke, is critical to national efforts for reducing

Table 1. Association between the presence of stroke and knowledge of stroke warning signs

\begin{tabular}{|c|c|c|c|}
\hline Variable & Model 1 & Model 2 & Model 3 \\
\hline \multicolumn{4}{|l|}{ Sudden numbness or weakness $\left(S_{1}\right)$} \\
\hline Non-stroke controls $(n=8,584)$ & 1.00 & 1.00 & 1.00 \\
\hline Stroke survivors $(n=382)$ & $1.30(1.01-1.66)$ & $1.44(1.12-1.86)$ & $1.42(1.10-1.83)$ \\
\hline Family members of stroke survivors $(n=279)$ & $1.00(0.76-1.31)$ & $1.00(0.76-1.32)$ & $1.00(0.76-1.32)$ \\
\hline \multicolumn{4}{|c|}{ Sudden difficulty speaking or understanding speech $\left(\mathrm{S}_{2}\right)$} \\
\hline Non-stroke controls & 1.00 & 1.00 & 1.00 \\
\hline Stroke survivors & $1.27(0.99-1.63)$ & $1.57(1.21-2.03)$ & $1.54(1.19-1.99)$ \\
\hline Family members of stroke survivors & $1.03(0.78-1.36)$ & $1.07(0.81-1.42)$ & $1.07(0.81-1.43)$ \\
\hline \multicolumn{4}{|l|}{ Sudden dizziness $\left(\mathrm{S}_{3}\right)$} \\
\hline Non-stroke controls & 1.00 & 1.00 & 1.00 \\
\hline Stroke survivors & $1.58(1.21-2.06)$ & $1.91(1.45-2.50)$ & $1.89(1.44-2.48)$ \\
\hline Family members of stroke survivors & $1.00(0.76-1.32)$ & $1.03(0.78-1.37)$ & $1.03(0.78-1.37)$ \\
\hline \multicolumn{4}{|l|}{ Sudden visual impairment $\left(\mathrm{S}_{4}\right)$} \\
\hline Non-stroke controls & 1.00 & 1.00 & 1.00 \\
\hline Stroke survivors & $0.99(0.81-1.23)$ & $1.18(0.95-1.46)$ & $1.17(0.95-1.46)$ \\
\hline Family members of stroke survivors & $0.93(0.73-1.19)$ & $0.97(0.75-1.24)$ & $0.97(0.75-1.24)$ \\
\hline \multicolumn{4}{|l|}{ Sudden severe headache $\left(S_{5}\right)$} \\
\hline Non-stroke controls & 1.00 & 1.00 & 1.00 \\
\hline Stroke survivors & $1.11(0.90-1.38)$ & $1.34(1.08-1.67)$ & $1.33(1.07-1.66)$ \\
\hline Family members of stroke survivors & $0.83(0.65-1.05)$ & $0.84(0.66-1.08)$ & $0.84(0.66-1.08)$ \\
\hline \multicolumn{4}{|l|}{ Knowing more than three stroke warning signs } \\
\hline Non-stroke controls & 1.00 & 1.00 & 1.00 \\
\hline Stroke survivors & $1.27(0.99-1.62)$ & $1.57(1.22-2.01)$ & $1.53(1.19-1.97)$ \\
\hline Family members of stroke survivors & $0.95(0.73-1.24)$ & $1.01(0.77-1.33)$ & $1.01(0.77-1.33)$ \\
\hline \multicolumn{4}{|l|}{ Knowing all five stroke warning signs } \\
\hline Non-stroke controls & 1.00 & 1.00 & 1.00 \\
\hline Stroke survivors & $1.00(0.81-1.23)$ & $1.22(0.99-1.51)$ & $1.21(0.97-1.49)$ \\
\hline Family members of stroke survivors & $0.93(0.73-1.19)$ & $0.95(0.74-1.21)$ & $0.95(0.74-1.22)$ \\
\hline
\end{tabular}

Values are presented as odds ratio (95\% confidence interval). Model 1: unadjusted; Model 2: adjusted for gender, age, residence type, education level, marital status, monthly household income, and occupation; Model 3: further adjusted for diagnosis of hypertension and diagnosis of diabetes plus model 2. 
stroke mortality and morbidity. ${ }^{5}$ Targeted educational programs for both SS and FMS are needed to raise awareness of SWS in groups at high risk of stroke recurrence. In particular, knowledge of FMS may be more important than that of SS because many elderly SS with low education levels live with their offspring in Korea. In hospitals, effective and repeatable stroke education programs are needed for inpatients, outpatients, and their families. Moreover, in community settings, public education and engagements for increasing stroke knowledge will be helpful.

The present study has several limitations. In particular, this study used a closed-ended questionnaire to gain knowledge of SWS, although prior studies have shown that awareness of SWS is usually poor when open-ended questions are used. ${ }^{6}$ Compared to open-ended approaches, closed-ended approaches are likely to have positive responses because they can give the respondents an immediate prompt regarding what the correct answer should be. ${ }^{7}$ Furthermore, in-hospital stroke patients with acute or severe stroke were not included; only SS currently living in the community were included. Therefore, we may have overestimated the knowledge of SWS in SS. Despite these limitations, this is the first study in Korea to investigate whether SS and FMS are more aware of SWS than the general population.

In a community setting, SS but not FMS had a higher awareness of SWS than NSC. If SS and their families have accurate knowledge of SWS, they will be able to recognize stroke recurrence quickly and respond appropriately, thus reducing the disability and severity of stroke. Because SS are at a substantial risk of recurrence, ${ }_{1}^{1}$ in- and post-hospital education programs and national strategies for SS and FMS should be established.

\section{References}

1. Boysen G1, Truelsen T. Prevention of recurrent stroke. Neurol Sci 2000;21:67-72.

2. Mohan KM, Wolfe CD, Rudd AG, Heuschmann PU, Kolominsky-Rabas PL, Grieve AP. Risk and cumulative risk of stroke recurrence: a systematic review and meta-analysis. Stroke 2011;42:1489-1494.

3. Aarnio K, Haapaniemi E, Melkas S, Kaste M, Tatlisumak T, Putaala J. Long-term mortality after first-ever and recurrent stroke in young adults. Stroke 2014;45:2670-2676.

4. Rohweder G, Ellekjær $H$, Salvesen $\emptyset$, Naalsund $E$, Indredavik B. Functional outcome after common poststroke complications occurring in the first 90 days. Stroke 2015;46:65-70.

5. Ellis $C$, Egede LE. Ethnic disparities in stroke recognition in individuals with prior stroke. Public Health Rep 2008;123:514522.

6. Jones SP, Jenkinson AJ, Leathley MJ, Watkins CL. Stroke knowledge and awareness: an integrative review of the evidence. Age Ageing 2010;39:11-22.

7. Nicol MB, Thrift AG. Knowledge of risk factors and warning signs of stroke. Vasc Health Risk Manag 2005;1:137-147.

\footnotetext{
Correspondence: Young-Hoon Lee

Department of Preventive Medicine, Wonkwang University School of Medicine, 460 Iksan-daero, Iksan 54538, Korea

Tel: +82-63-859-1990

Fax: +82-63-859-1995

E-mail: Iyh8275@hanmail.net

Received: July 25, 2019

Revised: August 19, 2019

Accepted: September 23, 2019

This study was supported by Wonkwang University in 2018.

The author has no financial conflicts of interest.
} 